\title{
Psychological and Environmental Correlates of Well-being Among Undergraduate University Students
}

\author{
Trevor G Mazzucchelli and Emily Purcell
}

\section{*Correspondence:}

trevor.mazzucchelli@curtin.

edu.au

Psychological Wellbeing

Research Group, and Brain,

Behaviour and Mental Health

Research Group, School

of Psychology and Speech

Pathology, Curtin University,

PO Box 1987, Perth 6845,

Australia

\begin{abstract}
This study explored whether the university environment provides similar well-being enhancing elements to those that have been found in the workplace and school contexts. Whether psychological inflexibility accounts for well-being over and above personality and environmental influences was also explored. A representative sample of 163 undergraduate university students in an Australian university completed an online survey measuring the key constructs. Environmental influences assessed included financial resources, physical security, opportunity to use new skills, externally generated goals, variety, environmental clarity, interpersonal contact, and valued social position. Hierarchical multiple linear regression analyses were then conducted to test for predictors of three domains of subjective well-being: positive affect, negative affect, and life satisfaction. The results suggested that university context contributes significantly to undergraduate students' well-being by providing a valued social role, externally generated goals, and variety. Students' perception of their physical security was also an important influence on their well-being. These results are consistent with the literature on well-being and employment. Neuroticism significantly predicted negative affect, while psychological inflexibility accounted for unique variance in life satisfaction and negative affect even when personality and environmental influences were taken into account. The implications of these findings for enhancing undergraduate university students' well-being are discussed.
\end{abstract}

Keywords: Environmental influences, Happiness, Personality, Psychological inflexibility, Subjective well-being, University students

\section{Background}

The well-being of university students is an important research endeavour. Experiencing high levels of subjective well-being is considered to be a central criterion of positive mental health (Diener 1984). In addition to this, well-being has been found to not only be an outcome of favourable life circumstances such as academic success and satisfying relationships, but also a predictor and part cause of these outcomes (Lyubomirsky et al. 2005). Consequently, the well-being of students at university is important for influencing students' later attitudinal and career outcomes, but also outcomes that benefit communities and society at large.

(c) 2015 Mazzucchelli and Purcell. This article is distributed under the terms of the Creative Commons Attribution 4.0 International License (http://creativecommons.org/licenses/by/4.0/), which permits unrestricted use, distribution, and reproduction in any medium, provided you give appropriate credit to the original author(s) and the source, provide a link to the Creative Commons license, and indicate if changes were made. 
Subjective well-being (SWB) is described as a broad category of human experience made up of two distinct components: an affective component that consists of the relative frequency of positive and negative affect, and a cognitive component that is concerned with judgements of life and global satisfaction (Diener 1984; Diener et al. 1999). People with high levels of SWB report frequent positive affect, infrequent negative affect and high levels of satisfaction (Diener 1994; Diener et al. 1991).

The personality traits of extraversion and neuroticism are strongly and consistently linked with the positive and negative affective components of SWB respectively (DeNeve and Cooper 1998; Steel et al. 2008). Several explanations have been given to explain this link, but these can be classified into two general classes: instrumental and temperamental (McCrae and Costa 1991). According to instrumental explanations, personality traits affect SWB indirectly, through choice of situations or the experience of life events. In contrast, temperament theories propose that there is a direct link between personality and affect that does not arise from life events or life experiences. Many of these theories link extroversion and neuroticism to affect through reward and punishment psychobiological systems (e.g., Cantor and Sanderson 1999; Carver and Scheier 1990). In addition to personality, SWB has also been found to be influenced by life circumstances and external environmental influences such as marital status (Diener et al. 2000), culture (Oishi and Schimmack 2010; Triandis and Suh 2002) and income (Diener et al. 2010; Kahneman and Deaton 2010).

University students are reported to have insufficient financial resources to meet their needs, feel as though they are heavily burdened by assignments, exams and presentations, and are at significantly higher risk of mental health problems (Ansari et al. 2011; Stallman 2010). At the same time, it is possible that certain aspects of the university environment have the potential to be protective and enhance student well-being. For instance, tertiary study provides students with rich opportunities for socialisation, to pursue personally meaningful goals, and to learn and apply knowledge and skills.

Although student adaptation at university has been studied in some detail, most of this work has concerned academic success, with surprising little research being focused on subjective well-being. Of the work that has been completed a range of intriguing findings have been found. Lounsbury et al. (2009) reported that Values in Action character strengths (Peterson and Seligman 2004) were significantly and positively related to life satisfaction. Norvilitis and Reid (2012) examined academic, circumstantial, and personal predictors of four categories of college success including life satisfaction. They found that life satisfaction was predicted by parental encouragement of intellectual curiosity and fewer symptoms of attention deficit hyperactivity disorder. Gilbreath et al. (2011) conducted a study investigating the relationship between student-university fit and wellbeing in two universities in the USA. They theorised that university "fit" would be an important consideration in increasing student well-being and performance. Their results indicated that student well-being and satisfaction increased as the university environment increasingly met their needs and that the physical environment (e.g., an aesthetically pleasing environment) was more important than the social (e.g., enjoyable social life) or academic environment (e.g., a scholarly/intellectual campus climate).

When considering predictors of university students' well-being, it may also be useful to consider models that have been developed in related fields such as the workplace and 
schools. Research has shown that employment has a significant influence on SWB in adults (Fryer 1986; Jahoda 1982). As well as providing financial benefits, Jahoda's (1982) latent deprivation model suggests that employment satisfies a number of psychological needs that she claims are inherent to well-being. Jahoda attributes the decreases in SWB observed in unemployed adults to the absence of the enforced time structure provided by the workplace, which creates a sense of purposeless in the unemployed individual. Warr's (1987) model of well-being builds on this understanding of the psychological benefits of employment by suggesting that certain characteristics of the workplace can either facilitate or constrain personally important processes and activities important for well-being and mental health. These broad environmental features (termed principal environmental influences, PEIs) may include: the extent to which a person can control activities and events; the clarity of expectations and feedback; the opportunities provided for the person to use and develop his or her skills; the degree to which goals are generated by the environment; the extent to which there is variety in tasks to be undertaken; the quality and quantity of interpersonal contact the environment affords; and the extent to which the environment provides the individual with valued social status, money, and physical security. These PEIs have been found to have predictive utility in the context of employment and unemployment (Haworth 2004), as well as in other environmental contexts such as in family life and retirement (Warr 1987). Warr suggests that, well-being is influenced by the environment in a non-linear manner analogous to the effect of vitamins on physical health. Like vitamins, some PEIs such as availability of money can improve mental health, but not beyond a certain level. Other PEIs such as externally generated goals produce benefits up to a certain level beyond which increases would be detrimental (Warr 1986, 2007). Warr's model is consistent with other theories of well-being that suggest that there are universal human needs and that fulfillment of them is likely to enhance a person's feelings of well-being (e.g., Ryan and Deci 2000; Ryff and Keyes 1995).

Horstmanshof et al. (2008) applied the Warr model of well-being to a sample of Australian year 12 high school students. These authors found that when personality variables were controlled, school-related environmental factors contributed a significant amount of the variance in the well-being of school students. The school environment was found to provide similar opportunities and context to the work environment through structuring students' time, providing opportunities for social contact, and providing students with a valued social role. The most significant predictor of students' affective well-being scores was found to be time structure, which supports Jahoda's (1982) emphasis on the psychological benefits of structured time in giving purpose and meaning to an individual's daily life.

Jahoda (1982) suggested that the psychological benefits that are gained from employment may be present, to a lesser degree, in other societal institutions and contexts. Although this has been tested in high school students (Horstmanshof et al. 2008), it has yet to be investigated in the university context. One of the goals of the present study was to build upon the foundation of work on university student wellbeing by applying Warr's (1987) PEI model to better understand how the well-being enhancing opportunities provided by the university environment compares to those in the school and workplace. 
The concept of psychological flexibility may also be useful when considering students' well-being since it is purported to account for how individuals can navigate complex situational demands and engage in valued pursuits (such as university study) despite objective hardship or psychological distress (Kashdan and Rottenberg 2010). Psychological flexibility refers to the ability to persist or change behaviour while being aware of and in contact with thoughts and feelings, understanding the demands of the situation, and behaving in a way that is consistent with one's values (Hayes et al. 1999). Individuals displaying psychological flexibility are willing to experience unwanted thoughts and feelings while pursuing important personal goals and values and tend to display healthier personal and social functioning (Kashdan and Rottenberg 2010). Psychological inflexibility is the term used to describe the opposite of these processes. It refers to attempts to avoid or alter the form, frequency, or intensity of difficult private events which arise when pursuing goals or values. Psychological inflexibility is associated with a number of quality of life outcomes including poor job performance, and increased psychopathology, stress, pain, and negative affectivity (Kashdan and Rottenberg 2010).

In summary, the aim of this study was to expand on the current knowledge of the influences on university students' well-being. The study replicates and extends the work of Horstmanshof et al. (2008) by using more commonly used measures of SWB in a university rather than a school student population. This study also investigates the contribution of psychological inflexibility in order to gain a greater understanding of a personal factor that has the potential to be subject to intervention in order to increase SWB in students. We hypothesised that after controlling for demographic variables, extraversion and neuroticism, and environmental influences (financial resources, physical security, opportunity to use new skills, externally generated goals, variety, environmental clarity, interpersonal contact, and valued social position) would account for a significant proportion of the variance in satisfaction with life (SWL), positive affect (PA) and negative affect (NA). It was also hypothesised that psychological inflexibility would account for a significant amount of the variance in SWL, PA, and NA, beyond that accounted for by demographic variables, extraversion, neuroticism, and environmental influences. We also tested for differences between male and female students since gender differences have previously been found in neuroticism, environmental comfort, perception of threat, and symptoms of anxiety and depression amongst high-school students (Horstmanshof et al. 2008).

\section{Methods}

Participants

A total of 232 individuals accessed the online survey, and of the 183 who completed the survey, 20 did not fit the undergraduate student status eligibility criteria. According to a priori power analysis, 123 participants were required in order to have adequate power $(0.80)$ to detect a medium effect $\left(f^{2}=0.15\right)$ at an alpha level of 0.05 . The final sample size of 163 participants, therefore, adequately powered the analyses. The sample consisted of 63 male (38.7\%) and 100 female (61.3\%) undergraduate university students, aged between 18 and 47 years $(M=21.26, S D=4.41)$. All areas of study available at Curtin University were represented with the majority of the participants studying health sciences $(36.8 \%)$, followed by engineering and mining (20.2\%), business, management 
and law (14.7\%), and the arts and creative industries (11.7\%). The remainder of the participants were studying: information technology and computing; education; architecture and construction; physical sciences and mathematics; culture, language and indigenous; and agriculture, environment and sustainability (16.6\%). All years of undergraduate study were also represented with $27.0 \%$ of the sample in their first year, $32.5 \%$ in their second year, $26.4 \%$ in their third year, and $14.1 \%$ in their fourth year.

Measures

Well-being

The cognitive and affective components of SWB were measured using two independent scales. The cognitive component was measured using the Satisfaction with Life Scale (SWLS; Diener et al. 1985). This measure consists of five items (sample item: "I am satisfied with my life") on which participants rate their agreement on a 7-point Likert scale with endpoints strongly disagree and strongly agree. Higher scores represent higher levels of SWL. The scale is considered to provide an excellent measure of the cognitive component of well-being (Pavot and Diener 2008). In previous research alpha coefficients for the SWLS have ranged from 0.79 to 0.89 (Pavot and Diener 1993). The alpha coefficient for the present study was 0.88 .

The affective component of SWB was measured using the Positive and Negative Affect Schedule (PANAS; Watson et al. 1988). This scale required participants to indicate the extent to which they have felt each of 10 negative (e.g., "distressed") and 10 positive (e.g., "interested") affects within the past year on a 5-point Likert scale with endpoints very slightly or not at all and extremely. According to Watson et al. (1988) the PANAS scales provide reliable, precise and largely independent measures of PA and NA, regardless of the population studied or the time frame used. They reported alpha coefficients ranging from 0.90 to 0.86 for PA and 0.87 to 0.84 for NA. The alpha coefficients for the present study were 0.88 for PA and 0.87 for NA.

\section{Personality}

The 12-item neuroticism and extraversion subscales of the short-scale Eysenck Personality Questionnaire-Revised (EPQ-R; Eysenck et al. 1985) were used to measure personality variables. Higher scores represent higher levels of extraversion (sample item: "Are you a talkative person?") and neuroticism (sample item: "Does your mood often go up and down?"). The EPQ-R is a well-validated measure with the neuroticism and extraversion subscales, in particular, being recognised as valid measures of their constructs (Eysenck and Eysenck 1991). Francis et al. (1992) reported alpha coefficients ranged from 0.87 to 0.78 for the extraversion subscale and 0.82 to 0.79 for the neuroticism subscale. The alpha coefficients for the present study were 0.86 for extraversion and 0.80 for neuroticism.

\section{Environmental Influences}

The environmental influences proposed by Warr (1987) were measured using a modified version of the Principle Environmental Influences Questionnaire (PEIQ; Haworth 1997). This scale includes two context-free subscales, and seven subscales that Haworth considers context specific. The context-free subscales consist of a three-item financial 
resources subscale (sample item: "Do you find that a shortage of money stops you engaging in activities" with a 5-point scale with endpoints very often and never); a 3-item physical security scale (sample item: "Do you ever feel threatened in some way?" with a 7-point scale with endpoints never and all the time). The context-specific subscales consist of a 4-item opportunity for control scale (sample item: "Much of the day I can choose the way in which I carry out my tasks"), a 4-item opportunity for skill use (sample item: "I feel as though I am learning a great deal"), a 7-item externally generated goals scale (sample item: "My university degree provides me with many targets/goals which I have to try and achieve"), a 4-item variety scale (sample item: "I carry out a wide range of activities in an average day"), a 4-item environmental clarity scale (sample item: "Sometimes I don't really know what people expect of me" [reverse scored]), a 4-item opportunity for interpersonal contact scale (sample item: "I see a lot of my university friends"), and a 6-item valued social position scale (sample item: "Society in general respects people like me"). All of the responses on these seven subscales were measured on a 7-point scale with endpoints of completely agree and completely disagree. The wording of some of the items in this measure were modified to reflect the university rather than the workplace environment. Higher scores indicated, respectively, more financial resources, greater physical security, more opportunity for control, more externally generated goals, more variety, greater environmental clarity, more opportunity for social contact, and greater valued social position. In the present study the internal reliability coefficients for the subscales were 0.80 (financial resources), 0.55 (physical security; one item [1] was removed to improve the internal reliability), 0.61 (externally generated goals; three items $[8,19,30]$ were removed), 0.73 (variety), 0.70 (environmental clarity; two items [3, 31] were removed), 0.70 (opportunity for interpersonal contact), and 0.72 (valued social position; one item [33] was removed). Due to unacceptable and poor internal reliability of the opportunity for control and opportunity for skill use scales, items from these scales were combined (removing 2, 7, 16, 18, and 29), to create a new scale relating to the opportunity to use new skills. This scale had an internal reliability of 0.61 . Overall, the internal reliabilities of these PEIQ scales are similar to a previous study where internal reliabilities ranged from 0.55 to 0.71 (Horstmanshof et al. 2008).

\section{Psychological Inflexibility}

Psychological inflexibility was measured using the seven-item Acceptance and Action Questionnaire (AAQ-II, Bond et al. 2011). This scale is scored on a 7-point scale with endpoints never true and always true (sample item: "My painful experiences and memories make it difficult for me to live a life that I would value") with higher scores indicating greater levels of psychological inflexibility. AAQ-II scores predict a range of outcomes that are consistent with the underling theory including mental health and work absenteeism (Bond et al. 2011). Bond et al. (2011) reported alpha coefficients ranging from 0.78 to 0.88 . The alpha coefficient for the present study was 0.91 .

\section{Procedure}

This study employed a survey design with a non-probability sample. Ethics approval for this study was granted by the Curtin University Human Research Ethics Committee. An invitation to participate in the study was distributed to Curtin University students using 
a Curtin University undergraduate social media page with data being collected via an online 111-item survey.

\section{Results}

Means and standard deviations for all variables are presented in Table 1 . We tested for differences between male and female students by conducting a series of independent sample $t$ tests. To avoid Type 1 errors, a Bonferroni correction of $\alpha<0.0042(0.05 / 12)$ was applied. At this level, there were no gender differences between students. Bivariate correlations are reported in Table 2 . Three hierarchical multiple linear regression analyses were then conducted to test for predictors of the three domains of well-being. The dependent variables in these analyses were SWL, PA and NA. Since the demographic variables of age and gender and the environmental influence of financial resources were not found to be significantly associated with the dependent variables they were excluded from the analyses. The personality variables (extraversion and neuroticism) were entered at Step 1 to control for their effect. When significantly associated with the dependent variable, the environmental influences (physical security, opportunity to use new skills, externally generated goals, variety, environmental clarity, interpersonal contact, and valued social position) were entered at Step 2. Finally, psychological inflexibility was entered at Step 3 to determine whether this variable would make a contribution above and beyond the previously entered predictors.

\section{Satisfaction with Life}

At Step 1 extraversion and neuroticism significantly predicted $S W L, F(2,160)=28.72$, $p<0.001$, accounting for $26.4 \%$ of the variance. Both neuroticism $\left(\beta=-0.42, s r^{2}=0.16\right)$ and extraversion $\left(\beta=0.18, s r^{2}=0.03\right)$ made significant individual contributions, with students reporting lower levels of neuroticism and higher levels of extraversion also

Table 1 Summary data for all study variables

\begin{tabular}{|c|c|c|c|c|c|c|c|}
\hline & \multicolumn{2}{|c|}{ Total $(N=163)$} & \multicolumn{2}{|c|}{ Female $(n=100)$} & \multicolumn{2}{|c|}{ Male $(n=63)$} & \multirow[t]{2}{*}{$t$} \\
\hline & $M$ & $S D$ & $M$ & $S D$ & $M$ & $S D$ & \\
\hline Satisfaction with life & 23.04 & 6.82 & 22.79 & 6.83 & 23.46 & 6.84 & 0.61 \\
\hline Positive affect & 34.65 & 7.06 & 34.57 & 7.24 & 34.79 & 6.81 & 0.20 \\
\hline Negative affect & 26.29 & 8.05 & 26.85 & 7.76 & 25.41 & 8.49 & -1.11 \\
\hline Neuroticism & 6.69 & 3.21 & 7.35 & 3.02 & 5.65 & 3.26 & $-3.39^{* *}$ \\
\hline Extraversion & 7.59 & 3.52 & 7.79 & 3.62 & 7.26 & 3.36 & -0.92 \\
\hline Financial resources & 8.48 & 3.29 & 8.08 & 3.43 & 9.13 & 2.98 & $1.99^{*}$ \\
\hline Physical security & 9.41 & 2.30 & 9.23 & 2.14 & 9.69 & 2.52 & -1.27 \\
\hline Opp. to use new skills & 15.03 & 3.50 & 15.52 & 3.29 & 14.25 & 3.69 & $2.28^{*}$ \\
\hline Ext. generated goals & 20.90 & 3.81 & 21.05 & 3.97 & 20.65 & 3.56 & 0.65 \\
\hline Variety & 17.53 & 4.80 & 17.43 & 5.00 & 17.68 & 4.47 & -0.33 \\
\hline Environmental clarity & 7.36 & 3.30 & 7.45 & 3.41 & 7.21 & 3.13 & 0.46 \\
\hline Interpersonal contact & 18.38 & 5.05 & 18.31 & 5.32 & 18.49 & 4.62 & -0.22 \\
\hline Valued social position & 22.40 & 5.68 & 22.60 & 5.59 & 22.09 & 5.85 & 0.56 \\
\hline Psychological inflexibility & 25.80 & 10.58 & 26.02 & 10.66 & 25.46 & 10.54 & -0.32 \\
\hline
\end{tabular}




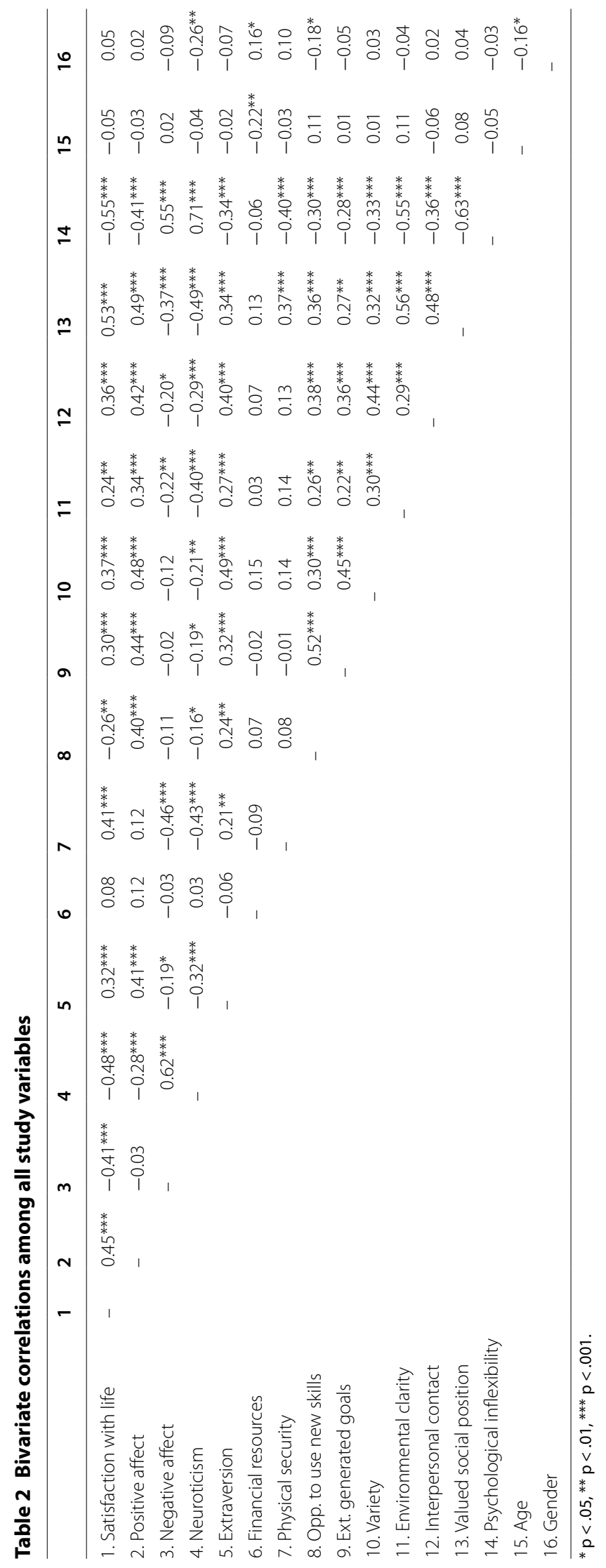


reporting more SWL. At Step 2, the environmental influences accounted for a further, significant $17.6 \%$ of the variance, $\Delta F(7,153)=6.87, p<0.001$. At this step a total of $40.7 \%$ of the variance was accounted for in SWL, with the most important predictors being valued social position $\left(\beta=0.33, s r^{2}=0.05\right)$, neuroticism $\left(\beta=-0.24, s r^{2}=0.04\right)$, physical security $\left(\beta=0.21, s r^{2}=0.02\right)$, variety $\left(\beta=0.17, s r^{2}=0.02\right)$, and environmental clarity $\left(\beta=-0.15, s r^{2}=0.01\right)$. At Step 3 , psychological inflexibility was found to account for a further significant $2.0 \%$ of variance, $\Delta F(1,152)=5.68, p=0.018$. At this step a total of $46.3 \%$ of the variance was accounted for in SWL, with the most important predictors being valued social position $\left(\beta=0.28, s r^{2}=0.04\right)$, psychological inflexibility $\left(\beta=-0.24, s r^{2}=0.02\right)$, physical security $\left(\beta=0.16, s r^{2}=0.02\right)$, environmental clarity $\left(\beta=-0.20, s r^{2}=0.02\right)$, and variety $\left(\beta=0.16, s r^{2}=0.02\right)$. Students who reported greater valued social position, less psychological inflexibility, more physical security, less environmental clarity, and more variety reported higher SWL. A summary of these results may be found in Table 3. If psychological inflexibility was added to the model at Step 2 instead of environmental influences, it accounted for a further significant $7.2 \%$ of variance, $\Delta F(1,159)=17.24, p<0.001$ (33.6\% of the variance in total) and was the only significant predictor of SWL.

\section{Positive Affect}

At Step 1 extraversion and neuroticism significantly predicted PA, $F(2,160)=18.69$, $p<0.001$, accounting for $18.9 \%$ of the variance. Both extraversion $\left(\beta=0.36, s r^{2}=0.11\right)$ and neuroticism $\left(\beta=-0.16, s r^{2}=0.02\right)$ made significant individual contributions, with students reporting higher levels of extroversion and lower levels of neuroticism reporting more PA. At Step 2, the environmental influences accounted for a further, significant $22.9 \%$ of the variance, $\Delta F(6,154)=10.09, p<0.001$. At this step a total of $41.8 \%$ of the variance was accounted for in PA, with the most important predictors being valued social position $\left(\beta=0.26, s r^{2}=0.04\right)$, variety $\left(\beta=0.21, s r^{2}=0.03\right)$ and externally generated goals $\left(\beta=0.16, s r^{2}=0.02\right)$. At Step 3 , psychological inflexibility was not found to account for any significant amount of the variance, $\Delta F(1,153)=0.98, p=0.324$. At

Table 3 Hierarchical multiple linear regression predicting satisfaction with life as a function of personality, environment and psychological inflexibility $(N=163)$

\begin{tabular}{|c|c|c|c|c|c|c|c|c|c|}
\hline \multirow{2}{*}{ Variables } & \multicolumn{3}{|l|}{ Step 1} & \multicolumn{3}{|l|}{ Step 2} & \multicolumn{3}{|l|}{ Step 3} \\
\hline & $B$ & $S E B$ & $\beta$ & $B$ & $S E B$ & $\beta$ & $B$ & $S E B$ & $\beta$ \\
\hline Neuroticism & -0.90 & 0.15 & $-0.42^{* * *}$ & -0.50 & 0.16 & $-0.24^{* *}$ & -0.27 & 0.19 & -0.13 \\
\hline Extraversion & 0.36 & 0.14 & $0.18^{*}$ & -0.00 & 0.14 & -0.00 & 0.00 & 0.14 & 0.00 \\
\hline Physical security & & & & 0.54 & 0.21 & $0.18^{*}$ & 0.47 & 0.21 & $0.16^{*}$ \\
\hline Opp. to use new skills & & & & 0.02 & 0.14 & 0.01 & -0.00 & 0.14 & -0.00 \\
\hline Ext. generated goals & & & & 0.20 & 0.14 & 0.11 & 0.18 & 0.14 & 0.10 \\
\hline Variety & & & & 0.25 & 0.11 & $0.17^{*}$ & 0.23 & 0.11 & $0.16^{*}$ \\
\hline Environmental clarity & & & & -0.32 & 0.16 & $-0.15^{*}$ & -0.42 & 0.16 & $-0.20^{*}$ \\
\hline Interpersonal contact & & & & 0.04 & 0.10 & 0.03 & 0.04 & 0.10 & 0.03 \\
\hline Valued social position & & & & 0.40 & 0.10 & $0.33^{* * *}$ & 0.34 & 0.11 & $0.28^{* *}$ \\
\hline Psychological inflexibility & & & & & & & -0.16 & 0.06 & $-0.24^{*}$ \\
\hline
\end{tabular}

$R^{2}=0.26$ for Step $1(p<0.001) ; \Delta R^{2}=0.18$ for Step $2(p<0.001) ; \Delta R^{2}=0.02$ for Step $3(p=0.018)$.

${ }^{*} p<0.05,{ }^{* *} p<0.01,{ }^{* * *} p<0.001$. 
this step a total of $42.2 \%$ of the variance was accounted for in PA, with the most important predictor remaining valued social position $\left(\beta=0.24, s r^{2}=0.03\right)$, variety $(\beta=0.20$, $\left.s r^{2}=0.02\right)$ and externally generated goals $\left(\beta=0.16, s r^{2}=0.02\right)$. Students who reported greater social position, more variety and more externally generated goals reported more PA. A summary of these results may be found in Table 4. If psychological inflexibility was added to the model at Step 2 instead of environmental influences, it accounted for a further significant $6.5 \%$ of variance $(25.5 \%$ of the variance in total), $\Delta F(1,159)=13.93$, $p<0.001$ and was a significant predictor of PA $\left(\beta=-0.37, s r^{2}=0.06\right)$ along with extraversion $\left(\beta=0.31, s r^{2}=0.08\right)$.

\section{Negative Affect}

At Step 1 extraversion and neuroticism significantly predicted NA, $F(2,160)=49.12$, $p<0.001$, accounting for $38.0 \%$ of the variance. Neuroticism $\left(\beta=0.62, s r^{2}=0.34\right)$ made a significant individual contribution, with students reporting lower levels of neuroticism reporting less NA. At Step 2, the environmental influences accounted for a further, significant $5.3 \%$ of the variance, $\Delta F(4,156)=3.65, p=0.007$. At this step a total of $43.3 \%$ of the variance was accounted for in NA, with the most important predictors being neuroticism $\left(\beta=0.52, s r^{2}=0.17\right)$ and physical security $\left(\beta=-0.23, s r^{2}=0.04\right)$. Students reporting lower levels of neuroticism and greater physical security reporting less NA. At Step 3, psychological inflexibility was found to account for a further significant $2.0 \%$ of the variance, $\Delta F(1,155)=5.74, p=0.018$. At this step a total of $45.4 \%$ of the variance was accounted for in NA, with the most important predictors again being neuroticism $\left(\beta=0.41, s r^{2}=0.08\right)$, psychological inflexibility $\left(\beta=0.24, s r^{2}=0.02\right)$, and physical security $\left(\beta=-0.21, s r^{2}=0.03\right)$. Students reporting lower levels of neuroticism, greater physical security, and lower psychological inflexibility reported less NA. A summary of these results may be found in Table 5. If psychological inflexibility was added to the model at Step 2 instead of environmental influences, it accounted for a further significant $2.6 \%$ of variance $(40.6 \%$ of the variance in total), $\Delta F(1,159)=6.91, p<0.01$ and was a significant predictor of NA $\left(\beta=0.23, s r^{2}=0.02\right)$ along with extraversion $(\beta=0.46$, $\left.s r^{2}=0.10\right)$.

Table 4 Hierarchical multiple linear regression predicting positive affect as a function of personality, environment and psychological inflexibility $(N=163)$

\begin{tabular}{|c|c|c|c|c|c|c|c|c|c|}
\hline \multirow[t]{2}{*}{ Variables } & \multicolumn{3}{|l|}{ Step 1} & \multicolumn{3}{|c|}{ Step 2} & \multicolumn{3}{|l|}{ Step 3} \\
\hline & $B$ & $S E B$ & $\beta$ & $B$ & $S E B$ & $\beta$ & B & $S E B$ & $\beta$ \\
\hline Neuroticism & -0.36 & 0.16 & $-0.16^{*}$ & 0.02 & 0.16 & 0.01 & 0.13 & 0.20 & 0.06 \\
\hline Extraversion & 0.71 & 0.15 & $0.36^{* * *}$ & 0.22 & 0.15 & 0.11 & 0.22 & 0.15 & 0.11 \\
\hline Opp. to use new skills & & & & 0.22 & 0.15 & 0.11 & 0.21 & 0.15 & 0.10 \\
\hline Ext. generated goals & & & & 0.29 & 0.14 & $0.16^{*}$ & 0.29 & 0.14 & $0.16^{*}$ \\
\hline Variety & & & & 0.31 & 0.12 & $0.21^{* *}$ & 0.30 & 0.12 & $0.20^{*}$ \\
\hline Environmental clarity & & & & 0.06 & 0.16 & 0.03 & 0.02 & 0.17 & 0.01 \\
\hline Interpersonal contact & & & & 0.07 & 0.11 & 0.05 & 0.07 & 0.11 & 0.05 \\
\hline Valued social position & & & & 0.33 & 0.11 & $0.26^{* *}$ & 0.30 & 0.11 & $0.24^{* *}$ \\
\hline Psychological inflexibility & & & & & & & -0.07 & 0.07 & -0.10 \\
\hline
\end{tabular}

$R^{2}=0.19$ for Step $1(p<0.001) ; \Delta R^{2}=0.23$ for Step $2(p<0.001) ; \Delta R^{2}=0.00$ for Step $3(p=0.324)$.

${ }^{*} p<0.05,{ }^{* *} p<0.01,{ }^{* * *} p<0.001$. 
Table 5 Hierarchical multiple linear regression predicting negative affect as a function of personality, environment and psychological inflexibility $(N=163)$

\begin{tabular}{|c|c|c|c|c|c|c|c|c|c|}
\hline \multirow[t]{2}{*}{ Variables } & \multicolumn{3}{|c|}{ Step 1} & \multicolumn{3}{|l|}{ Step 2} & \multicolumn{3}{|l|}{ Step 3} \\
\hline & $B$ & SE B & $\beta$ & $B$ & $S E B$ & $\beta$ & $B$ & $S E B$ & $\beta$ \\
\hline Neuroticism & 1.55 & 0.16 & $0.62^{* * *}$ & 1.29 & 0.19 & $0.52^{* * *}$ & 1.02 & 0.22 & $0.41^{* * *}$ \\
\hline Extraversion & 0.01 & 0.15 & 0.00 & 0.08 & 0.16 & 0.04 & 0.09 & 0.15 & 0.04 \\
\hline Physical security & & & & -0.82 & 0.24 & $-0.23^{* *}$ & -0.75 & 0.24 & $-0.21^{* *}$ \\
\hline Environmental clarity & & & & 0.14 & 0.18 & 0.06 & 0.26 & 0.19 & 0.11 \\
\hline Interpersonal contact & & & & -0.03 & 0.12 & -0.02 & -0.2 & 0.11 & -0.01 \\
\hline Valued social position & & & & -0.09 & 0.12 & -0.06 & -0.01 & 0.12 & 0.01 \\
\hline Psychological inflexibility & & & & & & & 0.18 & 0.08 & $0.24^{*}$ \\
\hline
\end{tabular}

\section{Discussion}

Previous research has emphasised the contribution of employment to well-being not just in terms of the monetary rewards, but also in terms of the role it plays in providing for other psychological needs such as social contact and time structure (Fryer 1986; Warr 1987). The primary aim of the present study was to investigate the influence of the university environment over and above personality on undergraduate university students' well-being. We hypothesised that the university setting would provide environmental elements similar to those found in employment settings and that these elements would contribute to university students' well-being. We also hypothesised that psychological inflexibility would account for a significant amount of the variance in well-being beyond that accounted for by other factors and that this, being a personal factor, would have important implications for interventions to increase well-being.

We found that personality variables were associated with well-being with a valence and strength consistent with previous research (Steel et al. 2008). Extraversion was positively associated with SWL and PA, although no longer predicted these variables when environmental elements were introduced into the regression models. These findings are consistent with instrumental hypotheses suggesting an indirect link between extraversion and PA and extraversion and SWL. Diener and colleagues (e.g., Ng and Diener 2014; Tay and Diener 2011) found that positive feelings were most associated with the fulfilment of social and respect needs and it is possible that the students' environment permitted the fulfilment of these psychological needs that are particularly associated with extraversion. An implication of this finding is that it might be possible to increase student's SWL and PA by increasing these PEIs.

Neuroticism was negatively associated with SWL and PA and negatively associated with NA. When environmental variables were taken into account, neuroticism no longer predicted PA, but continued to contribute unique variance to SWL and NA. However, when psychological inflexibility was added to the model neuroticism failed to contribute variance to SWL, but continued to contribute unique variance to NA. These findings suggest that the relationship between neuroticism and PA is mediated by environmental factors, that the relationship between neuroticism and SWL is mediated by psychological inflexibility, and that there is a direct link between neuroticism and NA. The "large" relationship between neuroticism and NA has been reported previously and it has been 
suggested that these two constructs are conceptually very similar and may share common physical underpinnings (e.g., serotonin; Steel et al. 2008; Zuckerman 2005). The finding that psychological inflexibility may mediate the relationship between neuroticism and SWL is intriguing. When experiencing negative thoughts and feelings, people scoring high in neuroticism have a tendency to ruminate or brood rather than engaging in adaptive behaviours such as problem solving or taking action toward personally valued goals (e.g., Hertel 1998; O’Brien and DeLongis 1996). It is plausible that this failure to take action may adversely impact on SWL.

Implications of these findings are that university based strategies aimed at the enhancement of student well-being may usefully include interventions that provide instruction in skills that will better equip students to manage the anxiety, moodiness and worry that characterises neuroticism, as well as stress which may precipitate negative mood states and mental health disorders. Students might also benefit from interventions that equip them with skills to detach from negative thoughts and feelings and to increase their tolerance for them while engaging in actions aligned with their interests and values. Interventions could include both brief, "light touch," interventions as well as more intensive cognitive-behavioural interventions where they are needed. Behavioural activation may be particularly suitable since it is a parsimonious approach that has been demonstrated to be effective in a university setting for both depression and anxiety and to increase levels of well-being in both individuals with and without a mental health condition (Gawrysiak et al. 2009; Mazzucchelli et al. 2009a, 2009b, 2010). Behavioural activation involves the use of a variety of strategies such as self-monitoring and scheduling activities to increase participants' engagement in adaptive activities that are typically associated with pleasure or mastery (Dimidjian et al. 2011).

As hypothesised, when personality variables were controlled, environmental elements proposed by Warr (1987) were found to account for a significant amount of the variance in SWL, PA, and NA. Students' SWL was positively related to with valued social position, physical security, and variety, but negatively related with environmental clarity. In terms of affective well-being, whereas students' PA was associated with valued social position, variety, and externally generated goals, students' NA was associated with physical security. Together, the findings suggest that university provides benefits to students in terms of providing a valued social role, externally generated goals, and variety. These findings are consistent with findings from studies involving adults in employment settings (e.g., Fryer 1986; Warr 1987) and more recently with secondary school students (Horstmanshof et al. 2008) and indicate the importance of these environmental influences in terms of determining well-being.

Providing a valued social position was found to be a predictor of both SWL and PA. The items of this subscale relate particularly to respondent's recognition that his or her efforts are making a contribution to others and the community at large. This finding appears to run contrary to the view that pleasure is merely about satisfying one's own needs, but is consistent with Jahoda's (1982) view that contributing to broader social structures can give personal esteem and social status. This finding, replicates Horstmanshof et al's (2008) findings and suggests that tertiary study has the potential to support students' well-being through providing a role that is held in esteem, providing opportunities to contribute to society in the present, and facilitating students' aspirations with 
respect to their future contributions to society. This finding is also consistent with previous research that has found that the experience of respect is a key predictor of positive feelings and may reflect a psychological need (Ng and Diener 2014; Tay and Diener 2011). The finding may also suggest that providing more opportunities for students to have a presence in the community through experiential education and contribute through community practicums could feasibly enhance well-being.

Externally generated goals was an important predictor for PA. This finding is consistent with Jahoda's (1982) model of well-being that emphasises the benefits of enforced time structure in terms of providing a sense of purpose and meaning. It is possible that time structure contributes toward fulfilling the psychological need for purpose in life, thus enhancing students' SWL and PA. Research has demonstrated that having valued goals is associated with well-being and that PA, in particular, is associated with making progress on those goals (Carver and Scheier 1990; Emmons 1986; King et al. 1998). This finding also indicates the relevance of psychological interventions that emphasise instruction in effective goal setting, time management, and scheduling of activities, again reinforcing the relevance of behavioural activation interventions for this population.

Variety emerged as an important predictor for SWL and PA. This finding is consistent with the idea that a role which provides diverse requirements and which introduces novelty and breaks up uniformity of activity is likely to have a positive impact on wellbeing (Warr 1987). People tend to seek variety in their behaviour (McAlister 1982; Ratner et al. 1999), perhaps because a certain amount of change is innately pleasurable and stimulating (Berlyne 1970; Rolls et al. 1981).

Environmental clarity was as an important predictor of SWL. Clarity refers to a range of perceived environmental features which make it possible for a student to understand what is expected or required, feedback on how he or she is performing, and what the consequences or outcomes will be both in the short-term and in the longer term in terms of a likely life course. Role ambiguity and conflict has been particularly studied in relation to the workplace and found to be associated with negative affect and depression (e.g., Schmidt et al. 2014), it was therefore interesting that in the present research environmental clarity was a better predictor of SWL than NA and that greater levels of clarity were associated with decrements in SWL. This appears to be the case where it is possible to get too much of a good thing. Warr (2007) noted that at very high levels of environmental clarity, events may become entirely predictable and a fixed set of role requirement may not permit any new experiences or the opportunity for further skill development. The implication for universities would appear to be to not attempt to control events too tightly and to ensure that there is scope for students to take some risks in the interest of skill development.

Physical security was a significant predictor of both SWL and NA. Because the questions asking about safety and threat were not specific to the university setting, it is not possible to draw conclusions about the university environment. Nevertheless, it is important that universities ensure students feel safe and secure. Indeed, Gilbreath et al. (2011) found that students emphasised the physical aspects of the environment (including safety) more than social and academic aspects when they described their ideal university (Gilbreath et al. 2011). While the relationship between perceptions of safety and well-being for students at school is well recognised and this has resulted in 
whole-of-school interventions to address bullying and victimisation, this relationship receives less attention at tertiary education settings and is deserving of further investigation (Karim 2010).

Financial resources and interpersonal contact were found to have little predictive value for student well-being. At first glance it seems surprising that financial resources does not predict well-being among a population who report restrictions on their activities because of a shortage of finances. However, previous research has established that financial resources do not appear to have a strong relationship with well-being once basic needs are met (Diener and Biswas-Diener 2002). It might be assumed that, although a lack of financial resources limits participation in desired activities, the present sample had sufficient financial resources to meet their essential needs. Similarly, although peer friendships have been identified in the literature as playing a vital role in adolescent and employee well-being (Haworth 1997; Steinberg 2002), social contact played a minor role in predicting SWL and PA, and buffering against NA, in the present study. Perhaps the present sample already had sufficient opportunities for social interaction outside of the university context.

Psychological inflexibility was found to account for unique variance in SWL and NA even when personality and environmental influences were controlled. Psychological inflexibility was also negatively associated with PA, although no longer predicted this variable when environmental elements were introduced into the regression model (suggesting an indirect link between psychological inflexibility and PA). These findings are consistent with previous research that has found that psychological inflexibility accounts for variance in mental health over and above that accounted for by personality variables (Bond 2005 cited in Bond et al. 2006). Given the relationships between psychological inflexibility and SWL, NA and PA, undergraduate university students may benefit from interventions that may decrease psychological inflexibility.

The present study found no differences between male and female participants on any other measure when a Bonferroni correction was applied. This outcome differs to that of Horstmanshof et al. (2008) who found that female high-school students reported significantly higher levels of anxiety, depression, neuroticism, environmental discomfort, and perceived physical threat. The only measures in the present study which approached significance were that of neuroticism, opportunity to use new skills, and financial resources. Gender differences in neuroticism are commonly found, with women tending to report themselves as being moderately higher in this factor than men (e.g., Costa et al. 2001; Schmitt et al. 2008). However, it is not obvious why women should find more opportunities to use new skills and men would have more financial resources. Nevertheless, together, these results suggest that male and female students experience the university environment similarly and that any university based intervention would not need to take into account systematic differences in factors associated with gender.

\section{Suggestions for Future Research}

The present study represents an initial step in an important line of inquiry into the factors that influence SWB in an undergraduate university student population. A limitation of the study is that although the sample was representative of the university undergraduate student population, the sample was nevertheless small. As such, it would be desirable 
to replicate these results with a larger student sample to be more confident about the generalisability of the findings. At the same time, the fact that these findings are consistent with those of both adult workers and high-school students lends some confidence as to their validity.

The environmental influences were measured by the PEIQ, a self-report scale completed by the participants whose well-being we were studying. Although the internal consistency of 5 of the 8 subscales of the PEIQ fell within the good to acceptable range, the internal consistency of 3 of the 8 subscales (physical security, externally generated goals, opportunity to use new skills) were questionable to poor, casting doubt that the items on these latter subscales were measuring the same latent variable. An avenue for future research would be to engage in further scale development to obtain more reliable measures of these environmental features. It may also be noted that because the environmental features were measured by the same people who were providing reports of their well-being, correlations between these variables are likely to have been inflated due to "common-method variance" (Podsakoff et al. 2003). Future research might seek to avoid this problem by obtaining descriptions of the university environment from other people or even objective measures of particular elements. Seeking objective indices would serve the additional benefit of permitting the investigation of the convergent validity of the environmental measures.

While this study examined the correlates of student well-being in the context of university, Ryff and Heidrich (1997) have found that for young adults, family and life outside of study are important predictors of well-being. Thus, it is important that future work examining the predictors of well-being of young adults not only consider the work or study environment, but also the broader environmental context in order to better understand what contributes to this population's well-being. Also, since environmental reward has been found to be a major predictor of depression (Carvalho et al. 2011), it would be of interest to investigate whether this may be a more proximal predictor of well-being than environmental elements per se. Finally, there is increasing recognition of the importance of not just focusing on a hedonic perspective of well-being, but also an eudemonic perspective that focuses on living well (Ryan and Deci 2001). The present study used measures of the former, but future research might usefully also incorporate eudemonic measures to give a more rounded perspective of well-being. This would also provide an opportunity to explore whether environmental factors directly influence undergraduate well-being, or whether their influences are due to their indirect impact via eudemonic well-being.

\section{Conclusion}

This study tested theories of well-being and employment on university students in order to determine the extent to which the university environment reflected the well-being enhancing elements of the workplace. To our knowledge, it is the first time that these theories and their PEI measures have been tested on university students. Overall, the measures were able to account significantly for the variance in the well-being variables of SWL, PA, and NA.

Consistent with Warr's (1987) model of well-being, the results of this study indicate that the university context provides some of the basic ingredients necessary for 
well-being; namely, a valued social role, an enforced time structure, and a variety of experiences. The perception of one's safety was also found to be a significant predictor of well-being and this may also be relevant when considering environmental change to enhance the well-being of students. Neuroticism significantly predicted negative affect, while psychological inflexibility accounted for unique variance in life satisfaction and negative affect even when personality and environmental influences were taken into account. This suggests that interventions to promote well-being should focus both on factors within the university that can promote an environment that will be beneficial for all students, as well as characteristics within individuals.

\section{Authors' contributions}

EP conceived of the study, participated in its design and coordination, helped perform the statistical analyses, and helped draft the manuscript. TGM participated in the design of the study, performed the statistical analyses, and drafted the manuscript. Both authors read and approved the final manuscript.

\section{Compliance with ethical guidelines}

Competing interests

The authors declare that they have no competing interests.

\section{Ethical approval}

This research was approved by the Curtin University Human Research Ethics Committee and complied with the National Statement on Ethical Conduct in Research (2007); National Health and Medical Research Council, Australian Research Council, \& Australian Vice-Chancellors' Committee (2007); National Statement on Ethical Conduct in Human Research 2007 (Updated May 2015); Canberra, Australia: Commonwealth of Australia. Available from: http://www.nhmrc.gov.au/ guidelines-publications/e72

Received: 9 April 2015 Accepted: 22 July 2015

Published online: 08 August 2015

\section{References}

Ansari, W., Stock, C., Snelgrove, S., Hu, X., Parke, S., Davies, S., et al. (2011). Feeling healthy? A survey of physical and psychological wellbeing of students from seven universities in the UK. International Journal of Environmental Research and Public Health, 8, 1308-1323. doi:10.3390/ijerph8051308.

Berlyne, D. (1970). Novelty, complexity, and hedonic value. Perception and Psychophysics, 8(5A), 279-286.

Bond, F. W., Hayes, S. C., Baer, R. A., Carpenter, K. M., Guenole, N., Orcutt, H. K., et al. (2011). Preliminary psychometric properties of the Acceptance and Action Questionnaire- II: A revised measure of psychological inflexibility and experiential avoidance. Behavior Therapy, 42, 676-688. doi:10.1016/j.beth.2011.03.007.

Bond, F. W., Hayes, S. C., \& Barnes-Holmes, D. (2006). Psychological flexibility, ACT and organizational behavior. In S. C. Hayes, F. W. Bond, D. Barnes-Holmes, \& J. Austin (Eds.), Acceptance and mindfulness at work (pp. 25-54). Binghamton: Haworth Press.

Cantor, N., \& Sanderson, C. A. (1999). Life task participation and well-being: The importance of taking part in daily life. In D. Kahneman, E. Diener, \& N. Schwarz (Eds.), Well-being: The foundations of hedonic psychology (pp. 230-243). New York: Russell Sage Foundation.

Carvalho, J. P., Trent, L. R., \& Hopko, D. R. (2011). The impact of decreased environmental reward in predicting depression severity: Support for behavioral theories of depression. Psychopathology, 44, 242-252. doi:10.1159/000322799.

Carver, C. S., \& Scheier, M. F. (1990). Origins and functions of positive and negative affect: A control-process view. Psychological Review, 97, 19-35. doi:10.1037/0033-295X.97.1.19.

Costa, P, Jr, Terracciano, A., \& McCrae, R. R. (2001). Gender differences in personality traits across cultures: Robust and surprising findings. Journal of Personality and Social Psychology, 81, 322-331. doi:10.1037//0022-3514.81.2.322.

DeNeve, K. M., \& Cooper, H. (1998). The happy personality: A meta-analysis of 137 personality traits and subjective wellbeing. Psychological Bulletin, 124, 197-229. doi:10.1037/0033-2909.124.2.197.

Diener, E. (1984). Subjective well-being. Psychological Bulletin, 95, 542-575.

Diener, E. (1994). Assessing subjective well-being: Progress and opportunities. Social Indicators Research, 31, 103-157.

Diener, E., \& Biswas-Diener, R. (2002). Will money increase subjective well-being? A Literature Review and Guide to Needed Research. Social Indicators Research, 57, 119-169. doi:10.1007/978-90-481-2350-6_6.

Diener, E., Emmons, R., Larson, R., \& Griffen, S. (1985). The satisfaction with life scale. Journal of Personality Assessment, 449, 71-75. doi:10.1207/s15327752jpa4901_13.

Diener, E., Gohn, C., Suh, E., \& Oishi, S. (2000). Similarity of the relations between marital status and subjective well-being across cultures. Journal of Cross-Cultural Psychology, 31, 419-436. doi:10.1177/0022022100031004001.

Diener, E., Ng, W., Harter, J., \& Arora, R. (2010). Wealth and happiness across the world: Material prosperity predicts life evaluation, whereas psychosocial prosperity predicts positive feeling. Journal of Perosnality and Social Psychology, 99, 52-61. doi:10.1037/a0018066. 
Diener, E., Sandvik, E., \& Pavot, W. (1991). Happiness is the frequency not the intensity of positive versus negative affect. In F. Strack, M. Argyle, \& N. Schwarz (Eds.), Subjective well-being: An interdisciplinary perspective (pp. 119-140). Oxford: Pergamon.

Diener, E., Suh, E., Lucas, M., \& Smith, H. (1999). Subjective wellbeing: Three decades of progress. Psychological Bulletin, 125 , 276-302. doi:10.1037//0033-2909.125.2.276.

Dimidjian, S., Barrera, M, Jr, Martell, C., Munoz, R. F., \& Lewinsohn, P. M. (2011). The origins and current status of behavioral activation treatments for depression. Annual Review of Clinical Psychology, 7, 1-38. doi:10.1146/ annurev-clinpsy-032210-104535.

Emmons, R. A. (1986). Personal strivings: An approach to personality and subjective well-being. Journal of Personality and Social Psychology, 51, 1058-1068

Eysenck, H. J., \& Eysenck, S. B. J. (1991). Manual of the Eysenck personality scales. Sevenoaks: Hodder \& Stoughton.

Eysenck, S. B., Eysenck, H. J., \& Barrett, P. (1985). A revised version of the Psychoticism scale. Personality and Individual Differences, 6, 21-29. doi:10.1016/0191-8869(85)90026-1.

Francis, L. J., Brown, L. B., \& Philipchalk, R. (1992). The development of an abbreviated form of the revised Eysenck Personality Questionnaire (EPQR-A): Its use among students in England, Canada, the U.S.A. and Australia. Personality and Individual Differences, 13, 443-449.

Fryer, D. (1986). Employment deprivation and personal agency during unemployment. Social Behaviour, 1, 3-23.

Gawrysiak, M., Nicholas, C., \& Hopko, D. R. (2009). Behavioral activation for moderately depressed university students: Randomized controlled trial. Journal of Counseling Psychology, 56, 468-475. doi:10.1037/a0016383.

Gilbreath, B., Kim, T., \& Nichols, B. (2011). Person-environment fit and its effects on university students: A response to surface methodology study. Research in Higher Education, 52, 47-62. doi:10.1007/s11162-010-9182-3.

Haworth, J. (1997). Work, leisure and well-being. London: Routledge.

Haworth, J. (2004). Work, leisure and well-being. In J. T. Haworth \& A. J. Veal (Eds.), Work and leisure (pp. 168-183). New York: Routledge.

Hayes, S., Strosahl, K., \& Wilson, K. (1999). Acceptance and commitment therapy: Understanding and treating human suffering. New York: Guildford Press.

Hertel, P. T. (1998). Relation between rumination and impaired memory in dysphoric moods. Journal of Abnormal Psychology, 107, 166-172.

Horstmanshof, L., Punch, R., \& Creed, P. (2008). Environmental correlates of wellbeing among final-year high school students. Australian Journal of Psychology, 60, 101-111. doi:10.1080/00049530701477746.

Jahoda, M. (1982). Employment and unemployment: A social psychological analysis. Cambridge: Cambridge University Press.

Kahneman, D., \& Deaton, A. (2010). High income improves evaluation of life but not emotional well-being. Proceedings of the National Academy of Sciences of the United States of America, 107, 16489-16493. doi:10.1073/pnas.1011492107.

Karim, N. (2010). Bullying in universities: It exists. The Independent. http://www.independent.co.uk/news/education/ higher/bullying-in-universities-it-exists-1869267.html. Accessed 7 Jan 2014.

Kashdan, T. B., \& Rottenberg, J. (2010). Psychological flexibility as a fundamental aspect of health. Clinical Psychology Review, 30, 865-878. doi:10.1016/j.cpr.2010.03.001.

King, L. A., Richards, J. H., \& Stemmerich, E. (1998). Daily goals, life goals, and worst fears: Means, ends, and subjective wellbeing. Journal of Personality, 66, 713-744.

Lounsbury, J. W., Fisher, L. A., Levy, J., \& Welsh, D. P. (2009). An investigation of character strengths in relation to the academic success of college students. Individual Differences Research, 7, 52-69.

Lyubomirsky, S., King, L., \& Diener, E. (2005). The benefits of frequent positive affect: Does happiness lead to success? Psychological Bulletin, 131, 803-855. doi:10.1037/0033-2909.131.6.803.

Mazzucchelli, T., Kane, R., \& Rees, C. (2009a). Behavioral activation treatments for depression in adults: A meta-analysis and review. Clinical Psychology: Science and Practice, 16, 383-411. doi:10.1111/j.1468-2850.2009.01178.x.

Mazzucchelli, T. G., Kane, R. T., \& Rees, C. S. (2010). Behavioral activation interventions for well-being: A meta-analysis. Journal of Positive Psychology, 5, 105-121. doi:10.1080/17439760903569154.

Mazzucchelli, T. G., Rees, C. S., \& Kane, R. T. (2009b). Group behavioural activation and mindfulness therapy for the wellbeing of non-clinical adults: A preliminary open trial. The Cognitive Behaviour Therapist, 2, 256-271. doi:10.1017/ S1754470X09990201.

McAlister, L. (1982). A dynamic attribute satiation model of variety-seeking behavior. Journal of Consumer Research, 9, $141-150$.

McCrae, R. R., \& Costa, P. T. (1991). Adding Liebe und Arbeit: The full five-factor model and well-being. Personality and Social Psychology Bulletin, 17, 227-232. doi:10.1177/014616729101700217.

Ng, W., \& Diener, E. (2014). What matters to the rich and the poor? Subjective well-being, financial satisfaction, and postmaterialist needs across the world. Journal of Personality and Social Psychology, 107, 326-338. doi:10.1037/a0036856.

Norvilitis, J. M., \& Reid, H. M. (2012). Predictors of academic and social success and psychological well-being in college students. Education Research International, doi:10.1155/2012/272030.

O'Brien, T. B., \& DeLongis, A. (1996). The interactional context of problem-, emotion- and relationship-focused coping: The role of the big five personality factors. Journal of Personality, 64, 775-813.

Oishi, S., \& Schimmack, U. (2010). Culture and well-being: A new inquiry into the psychological wealth of nations. Perspectives on Psychological Science, 5, 463-471. doi:10.1177/1745691610375561.

Pavot, W., \& Diener, E. (1993). Review of the satisfaction with life scale. Psychological Assessment, 5, 164-172. doi:10.1007/978-90-481-2354-4_5.

Pavot, W., \& Diener, E. (2008). The satisfaction with life scale and the emerging construct of life satisfaction. The Journal of Positive Psychology, 3, 137-152. doi:10.1080/17439760701756946.

Peterson, C., \& Seligman, M. E. P. (2004). The Values in Action (VIA) classification of strengths. Washington, DC: American Psychological Association. 
Podsakoff, P. M., MacKenzie, S. B., Lee, J.-Y., \& Podsakoff, N. P. (2003). Common method biases in behavioral research: A critical review of the literature and recommended remedies. Journal of Applied Psychology, 88, 879-903. doi:10.1037/0021-9010.88.5.879.

Ratner, R. K., Kahn, B. E., \& Kahneman, D. (1999). Choosing less-preferred experiences for the sake of variety. Journal of Consumer Research, 26, 1-15.

Rolls, B. J., Rowe, E. A., Rolls, E. T., Kingston, B., Megson, A., \& Gunary, R. (1981). Variety in a meal enhances food intake in man. Physiology \& Behavior, 26, 215-221.

Ryan, R. M., \& Deci, E. L. (2000). Self-determination theory and the facilitation of intrinsic motivation, social development, and well-being. American Psychologist, 55, 68-78. doi:10.1037110003-066X.55.1.68.

Ryan, R. M., \& Deci, E. L. (2001). On happiness and human potentials: A review of research on hedonic and eudaimonic well-being. Annual Review of Psychology, 52, 141-166. doi:10.1146/annurev.psych.52.1.141.

Ryff, C. D., \& Heidrich, S. M. (1997). Experience and well-being: Explorations on domains of life and how they matter. International Journal of Behavioral Development, 20, 193-206. doi:10.1080/016502597385289.

Ryff, C. D., \& Keyes, L. M. (1995). The structure of psychological well-being revisited. Journal of Personality and Social Psychology, 69, 719-727.

Schmidt, S., Roesler, U., Kusserow, T., \& Rau, R. (2014). Uncertainty in the workplace: Examining role ambiguity and role conflict, and their link to depression-A meta-analysis. European Journal of Work and Organizational Psychology, 23, 91-106. doi:10.1080/1359432X.2012.711523.

Schmitt, D. P., Realo, A., Voracek, M., \& Allik, J. (2008). Why can't a man be more like a woman? Sex differences in Big Five personality traits across 55 cultures. Journal of Personality and Social Psychology, 94, 168-182. doi:10.1037/0022-3514.94.1.168.

Stallman, H. M. (2010). Psychological distress in university students: A comparison with general population data. Australian Psychologist, 45, 249-257. doi:10.1080/00050067.2010.482109.

Steel, P., Schmidt, J., \& Shultz, J. (2008). Refining the relationship between personality and subjective well-being. Psychological Bulletin, 134, 138-161. doi:10.1037/0033-2909.134.1.138.

Steinberg, L. (2002). Adolescence. New York: McGraw-Hill.

Tay, L., \& Diener, E. (2011). Needs and subjective well-being around the world. Journal of Personality and Social Psychology, 101, 354-365. doi:10.1037/a0023779.

Triandis, H. C., \& Suh, E. M. (2002). Cultural influences on personality. Annual Review of Psychology, 53, 133-160. doi:10.1146/annurev.psych.53.100901.135200.

Warr, P. (1986). A vitamin model of jobs and mental health. In G. Debus \& H. W. Schoroiff (Eds.), The psychology of work and organisation (pp. 157-164). Amsterdam: Elsevier Science.

Warr, P. (1987). Work, unemployment and mental health. Oxford: Clarendon Press.

Warr, P. (2007). Work, happiness, and unhappiness. Mahwah: Erlbaum.

Watson, D., Clark, L. A., \& Tellegen, A. (1988). Development and validation of a brief measure of positive and negative affect: The PANAS scales. Journal of Personality and Social Psychology, 54(6), 1063-1070.

Zuckerman, M. (2005). Psychobiology of personality. New York: Cambridge University Press.

\section{Submit your manuscript to a SpringerOpen ${ }^{\circ}$ journal and benefit from:}

- Convenient online submission

- Rigorous peer review

- Immediate publication on acceptance

- Open access: articles freely available online

- High visibility within the field

- Retaining the copyright to your article

Submit your next manuscript at $>$ springeropen.com 